\title{
Sand Waves along the Dutch Coast
}

HENDRIK J. VERHAGEN

Rijkswaterstaat, Road and Hydraulic Division, Delft (The Netherlands)

Published in Coastal Engineering (1989) 13: 129- 147. 129

\section{ABSTRACT}

Sand waves, defined as longshore wave-like movements of the shoreline, measured in a horizontal plane, are described along several stretches of the shoreline of The Netherlands. They have a celerity in the order of 50-200 m/yr, a period of 50- 150 years and an amplitude of 30- $500 \mathrm{~m}$. They are found along the whole Dutch shoreline. Analysis of sand waves shows that the assumed effect of groins might be very small along this shoreline. There are indications that groins did not have any long-term effect on coastal regression.

\section{INTRODUCTION}

At some coastlines of the world oscillatory movements can be observed. Bruun (1954) describes migrating sand humps along the Danish North Sea coast. The observed wave length is in the order of 2$3 \mathrm{~km}$ (near Lime Inlet). Bruun and Manohar (1963) observed migrating humps with a length of 100$300 \mathrm{~m}$ along the coast of Jupiter Island and South Palm Beach (Florida ). Along the coast of Aquitaine (France) Lorin and Migniot (1984) observed also "wagons sédimentaires", with an undetermined period. However, most of these observations cannot be worked out in detail, because a long series of data (appr. one century, measuring distance $1 \mathrm{~km}$ apart or less) was not available.

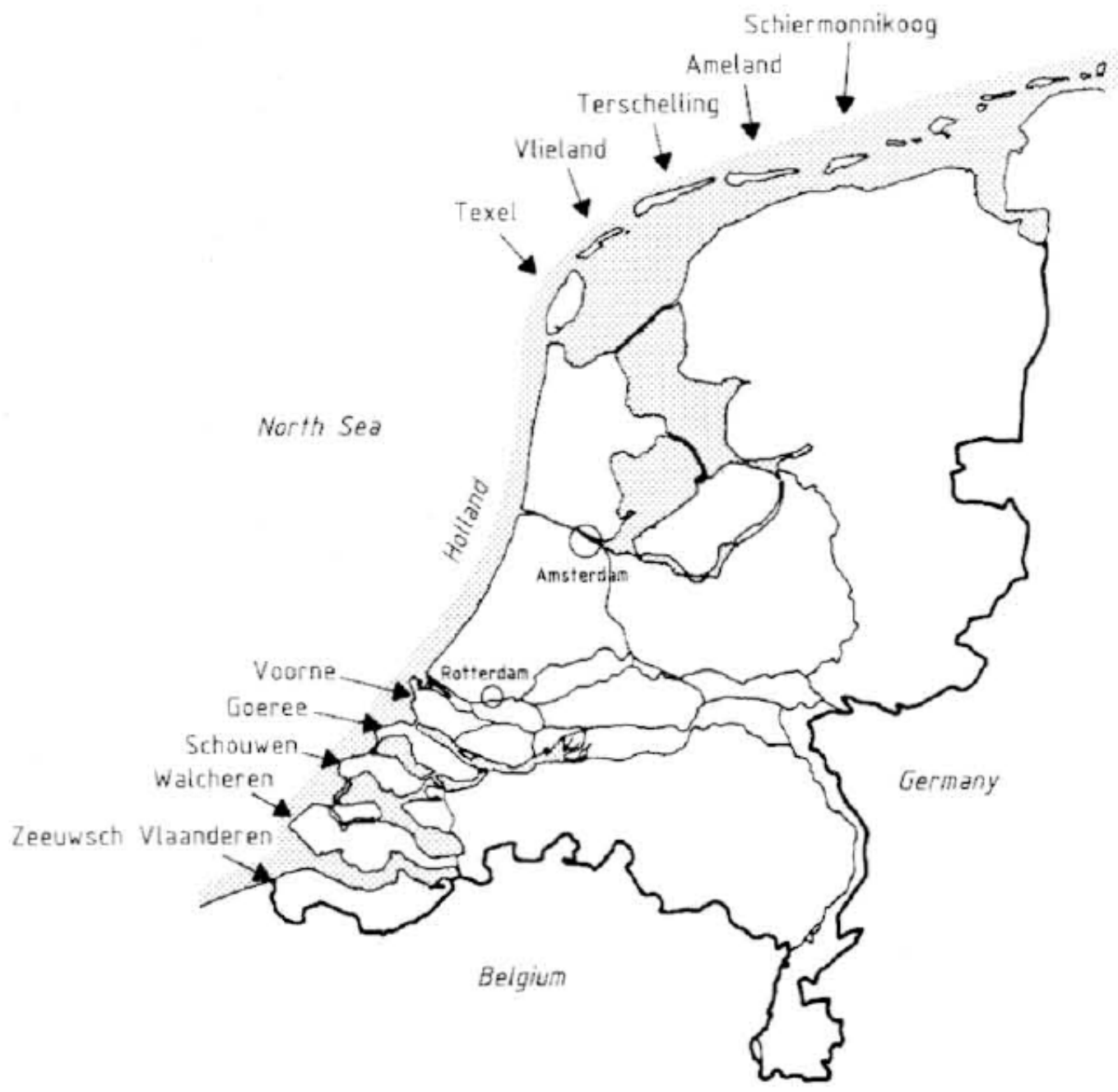

Figure 1: Coastal sections in the Netherlands 
In The Netherlands Ringma (1950) mentioned in an internal report remarkable oscillations in the position of the shoreline, which he called sand waves. He described a mass of sand (in his case approx. one million cubic meters) moving along the coast of Walcheren (see Fig. 1 for topographic names) with a celerity of $80 \mathrm{~m} / \mathrm{yr}$. He also concluded that the amount of sand in the wave decreased by $30,000 \mathrm{~m} 3$ per year. These waves were mentioned later on in other internal reports, but no real analysis was made. In 1968 Bakker published a mathematical description (Bakker, 1968) of the movement of sand waves based upon the Pelnard-Considère equation. Bakker fitted his mathematical description to sand waves on the isle of Vlieland. The approach of Bakker was however not used for practical coastal management, because of problems with t he accuracy in the prediction of the wave motion. Recently Maranus started a more thorough investigation of sand waves along the coast of Walcheren, which was reported in a Dutch publication (Maranus and Verhagen, 1987).

Further investigations have shown that sand waves occur along nearly the complete Dutch coast. They have a periodicity between 50 and 150 years. In this paper the word "sand wave" is used for a transversal wave-like movement of the shoreline, measured in a horizontal plane. The horizontal displacement of $\mathrm{t}$ he shoreline $\mathrm{y}$ can be written as a function of time and place along the shoreline (e.g. $\mathrm{y}=\mathrm{A} \cos (\omega \mathrm{t}+\mathrm{kx})$; $\mathrm{y}$ is posit ion of the shoreline, $\mathrm{x}$ is distance along the coast, $\mathrm{A}$ is amplitude, and $\mathrm{t}$ is time). In literature the word "sand wave" is also used for a non-moving bedform (e.g. Allen, 1980). It is not known if there is any relation between the two types of waves.

\section{GENERAL PROCEDURE}

In order to analyze sand waves a definition of shoreline is required (see Fig. 2). The average mean sea level (MSL) line is defined as shoreline, and can be obtained by a volume integration of the profile between high-water (HW) and low-water (LW). This procedure is only possible if full profile data are available. Unfortunately full profile data, covering a century, are only available along short stretches of the Dutch shoreline. For all the other stretches, the shoreline is defined as the mean value of $t$ he location of the HW-line and the LW-line Positions of $\mathrm{t}$ he HW-line and LW-line a re available since 1855 in points $1 \mathrm{~km}$ apart along the entire Dutch shoreline.

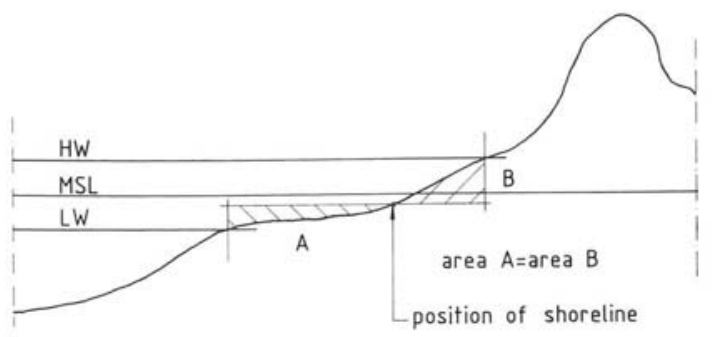

Figure 2: Definition of the shoreline

The position of the shoreline is plotted as a function of time, and the linear coastal regression is calculated for each place (Fig. 3a). In the next step the position relative to the regression is plotted (the residual position; see Fig. 3b) In this diagram the diagonals indicate the celerity of the sand wave. Besides the relative position also the relative coastal regression can be calculated. The relative coastal regression, expressed in $\mathrm{m} / \mathrm{yr}$ is defined as the derivative of the lines in Fig. 3b. The result of the calculations is that for every point along the coastline, and for every year the relative position and the relative coastal regression is known. Now it is possible to plot these values in a chart with the distance along the coast on the horizontal axis, and time along the vertical axis. Isolines for equal relative coastal regression can be drawn in this chart. In such a chart the sand waves can he observed as "diagonals". 

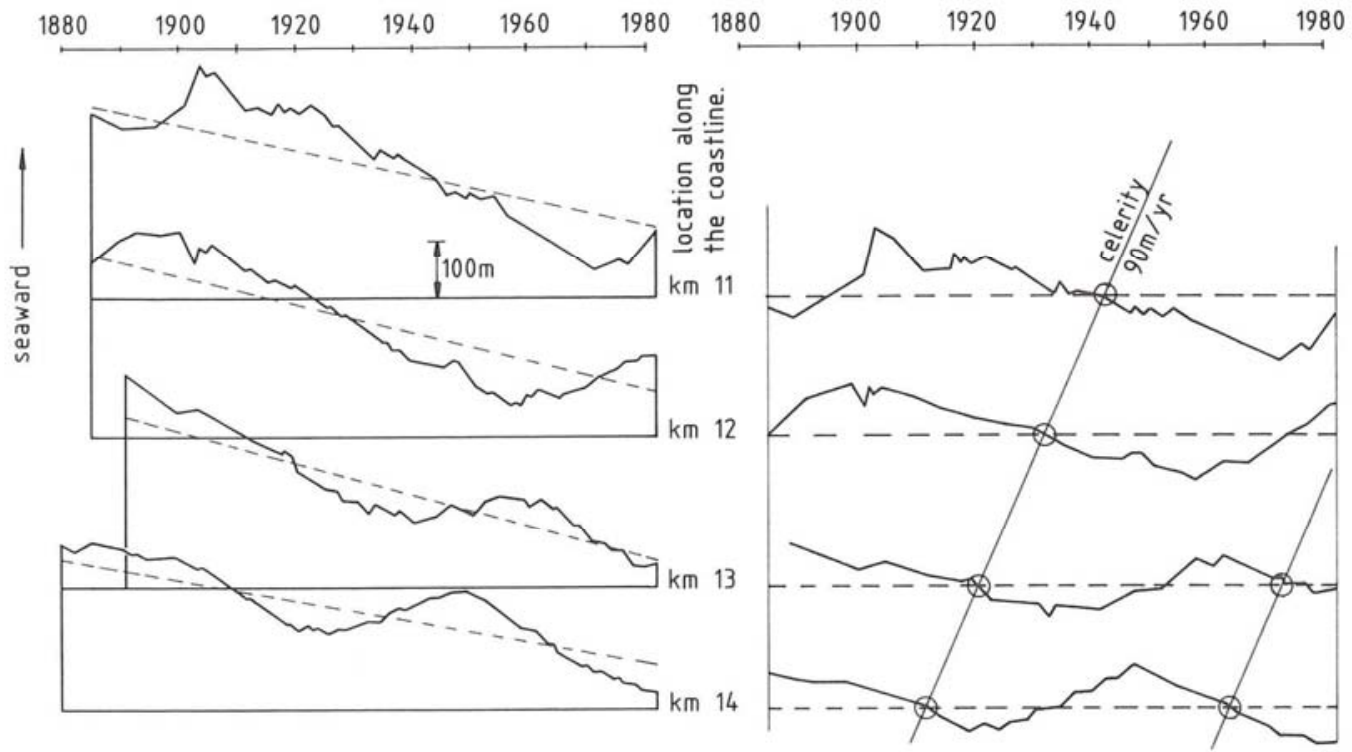

(a) absolute position of the shoreline

(b) residual position of the shoreline

Figure 3: Position of the shoreline as a function of time for four stations at the coast of Schouwen

\section{RESULTS FOR THE SHORELINE OF WALCHEREN}

For the northwestern coast of Walcheren profiles were available since 1882 at short intervals (200-250 $\mathrm{m})$. The procedure as described above resulted in the relative regression charts of Fig. 4 . Not only the shoreline (HW- LW), but also the inshore (MSL-3 - MSL-5 ) was analyzed. In this diagram "zero" means no coastal movement at that point and at that moment. It is either the crest or the trough of a sand wave. It can be seen in Fig. 4 that over the years the crest of the sand wave for the inshore zone moved from $\mathrm{km} 19$ in 1880 to $\mathrm{km} 15$ in 1955 . This is a celerity of $45 \mathrm{~m} / \mathrm{yr}$. From this diagram it is difficult to determine either period or wavelength. The period should be in the order of $130-150 \mathrm{yr}$, and the wavelength $7 \mathrm{~km}$. The amplitude is not constant. At the west side of the coastal section (km 18) the amplitude is approx. $250 \mathrm{~m}$, and decreases until almost zero near $\mathrm{km} \mathrm{13.2.} \mathrm{More} \mathrm{to} \mathrm{the} \mathrm{east} \mathrm{the}$ amplitude increases again, and near $\mathrm{km} 10.0$ the amplitude is approx. $300 \mathrm{~m}$. The change in amplitude can be explained by the fact that in reality a mass of sand moves along the coast, and that the local amplitude depends very much on beach slope and water depth.

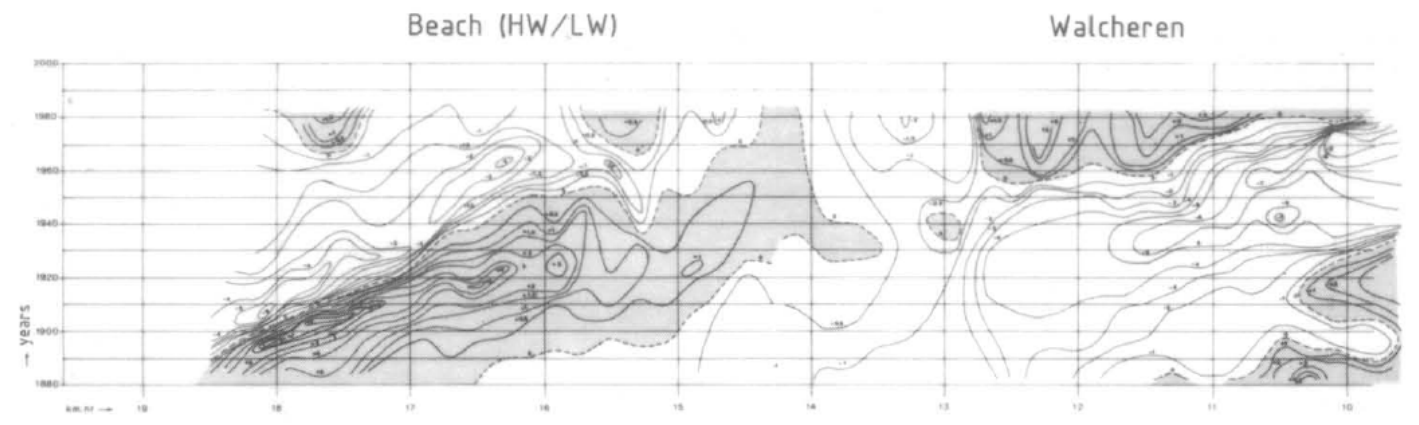

Inshore zone (msl-3/msl-5)

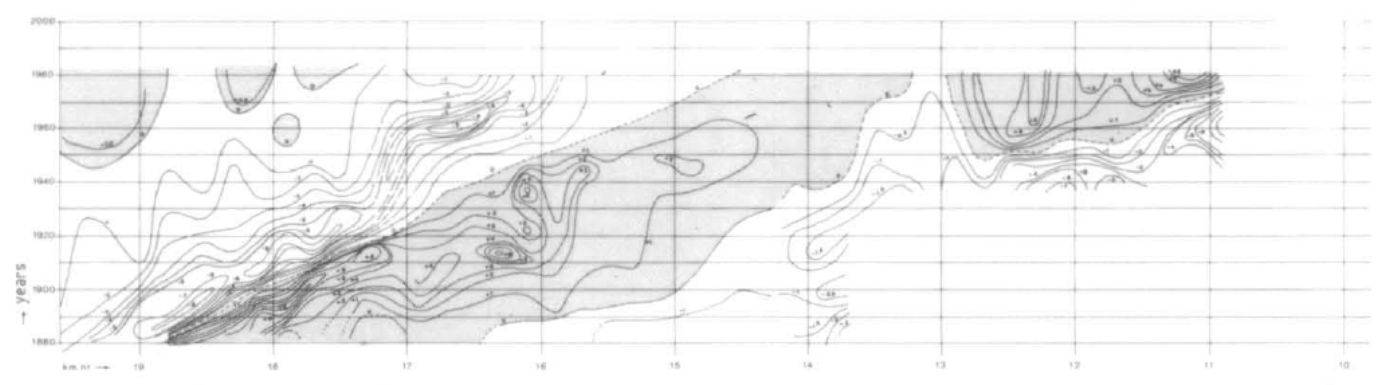

coastal movement in $m \mathrm{yr}^{-1}$ (accretion is positive)

Figure 4. Isolines of coastal regression along the coast of Walcheren 


\section{RESULTS FOR THE SHORELINE OF HOLLAND}

Along the entire coast of Holland, $118 \mathrm{~km}$ long, HW and LW data are available since 1855 (Holland is a province of The Netherlands). Only in shorter sections full profiles are available. In each kilometerpoint the shoreline is de fined as the average of the HW and LW position. The results are brought together in a relative position chart (Fig. 5; please note that the horizontal scale in Fig. 4 is different from Fig. 5). A phenomenon which can be observed in Fig. 5 is the horizontal band of shoreline positions in a more landward position in the period between 1875 and 1900.

Van Straaten (1961) has suggested that this erosion period is related to a change in the meteorological climate. In Fig. 6 can be seen that there is a distinct relation between the average position of the shoreline and the occurrence of more westerly winds. During the period around 1880 there was more precipitation than usual and somewhat lower mean-annual temperature. Unfortunately, no data are available concerning variations in the distribution of winds of different velocities during this period. It seems likely that a greater frequency of winds from the southwest and west is, in general, accompanied by a more frequent occurrence of storms from these same directions. Because the orientation of the shoreline between Hook of Holland and Den Helder is relatively constant, the effect of climatologic changes should be the same everywhere along the shoreline. In order to eliminate the effect of climatologic changes, it has been assumed that sand waves a re short in respect to the length of the shoreline and that the average position of a shoreline with sand waves is zero. With these assumptions it is possible to eliminate the climatologic effect by calculating the average shoreline position for the shoreline as a whole for every year apart (averaging a long horizontal lines in Fig. 5). The result is plotted in Fig. 7.

This figure gives the position of the shoreline of Holland as a function of time, after elimination of linear coastal regression and after elimination of sand waves. So only changes in shoreline are shown, which are valid for the shoreline as a whole. There are no local effects any more in this diagram. The lower part of Fig. 6 is based on Fig. 7. Using the data of Figs. 5 and 7 it is possible to construct a diagram in which only the effect of the sand wave is present. This is performed in Fig. 8. The sand waves, already present in Fig. 5, become more clear now. 


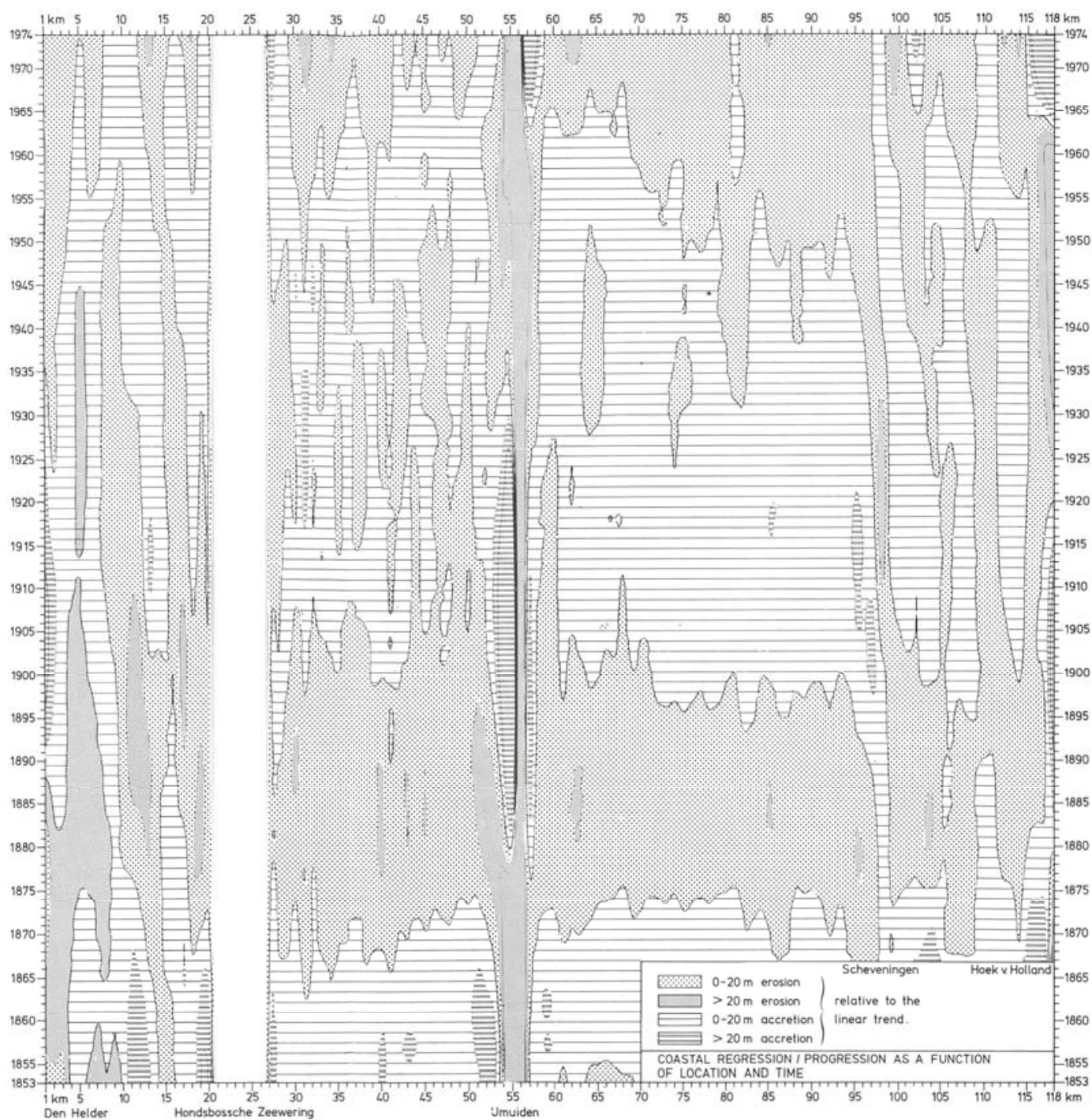

Figure 5. Isolines of coastal regression along the coast of Holland

In Fig. 8 the following effects have been eliminated:

- short-term shoreline fluctuations (order of one year);

- climatic changes which occur everywhere along the shoreline; and

- the long-term linear coastal regression for every point along the shoreline (order of 150 years and more).

So Fig. 8 can show only the following effects:

- periodic changes in shoreline position (sand waves) with periods between 5 and 100 years; and

- abrupt changes in coastal regression, for example due to the construction of works. 


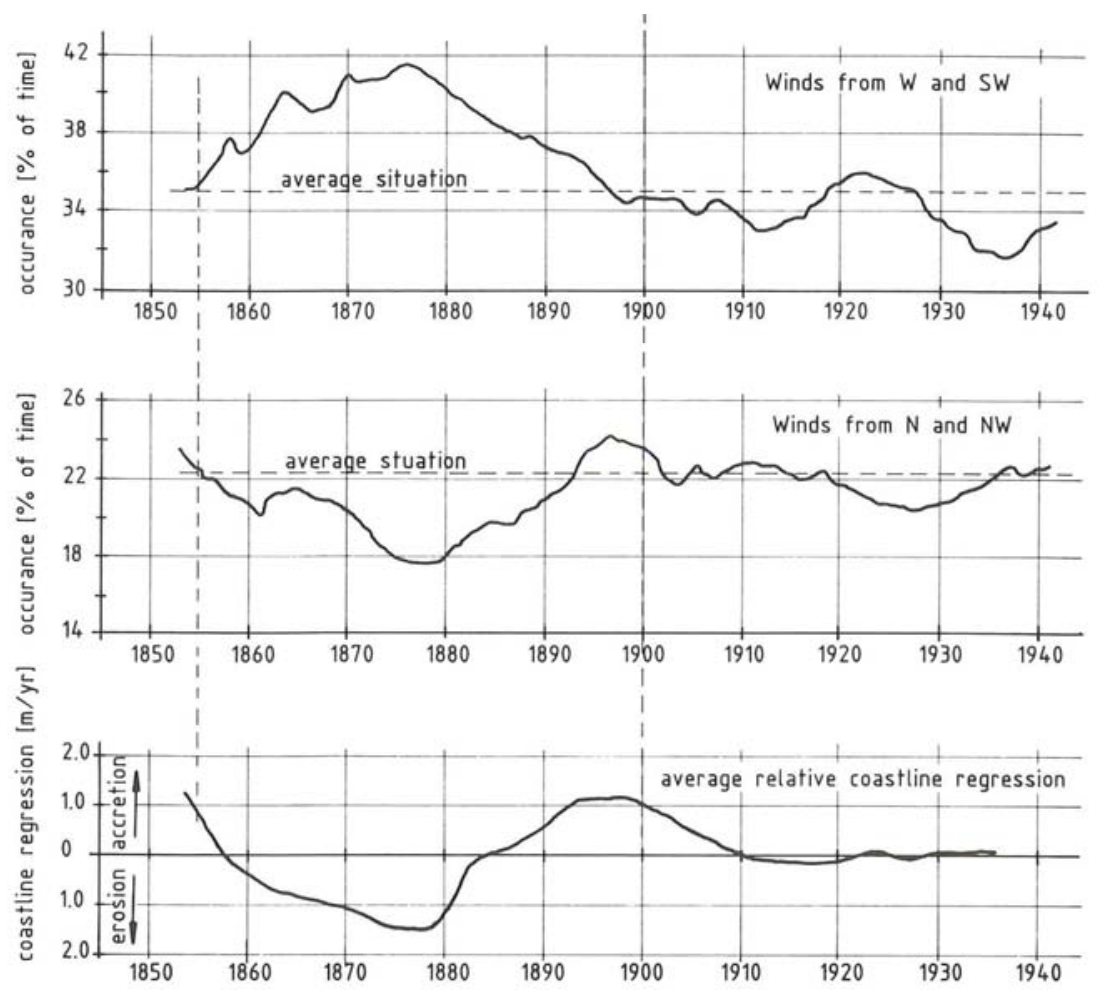

Figure 6. Frequencies of wind directions as a function of time

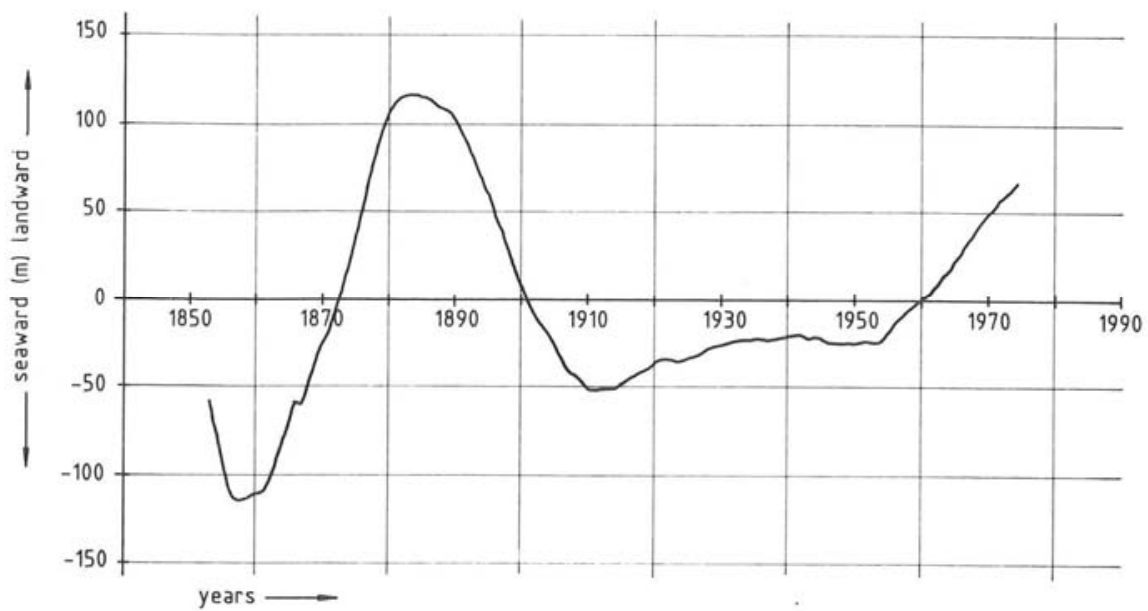

Figure 7. Changes in the average position of the shoreline of Holland

In Fig. 8 the sand waves are also indicated as shaded diagonal belts. The shaded area is the trough of the wave. The diagonals indicate waves with a celerity of $65 \mathrm{~m} / \mathrm{yr}$ and a wave period of $75-100 \mathrm{yr}$. Because the time span of data is more than is available at Walcheren, and especially because the length of the coast is much longer, the periodicity of the waves becomes more clear along this stretch of coastline. The waves are rather clear in the northern section $(\mathrm{km} \mathrm{1-20)}$ and the southern section $(\mathrm{km}$ 95-118). In the middle section the waves are less clear. The harbour moles of the port of IJmuiden show a strong local disturbance of the general pattern. The disturbance due to the moles of the ports of Scheveningen and Hook of Holland is less. It is remarkable that sand waves can be observed passing the moles of Scheveningen. Locally the amplitude of the wave is disturbed, celerity and period are not disturbed. 


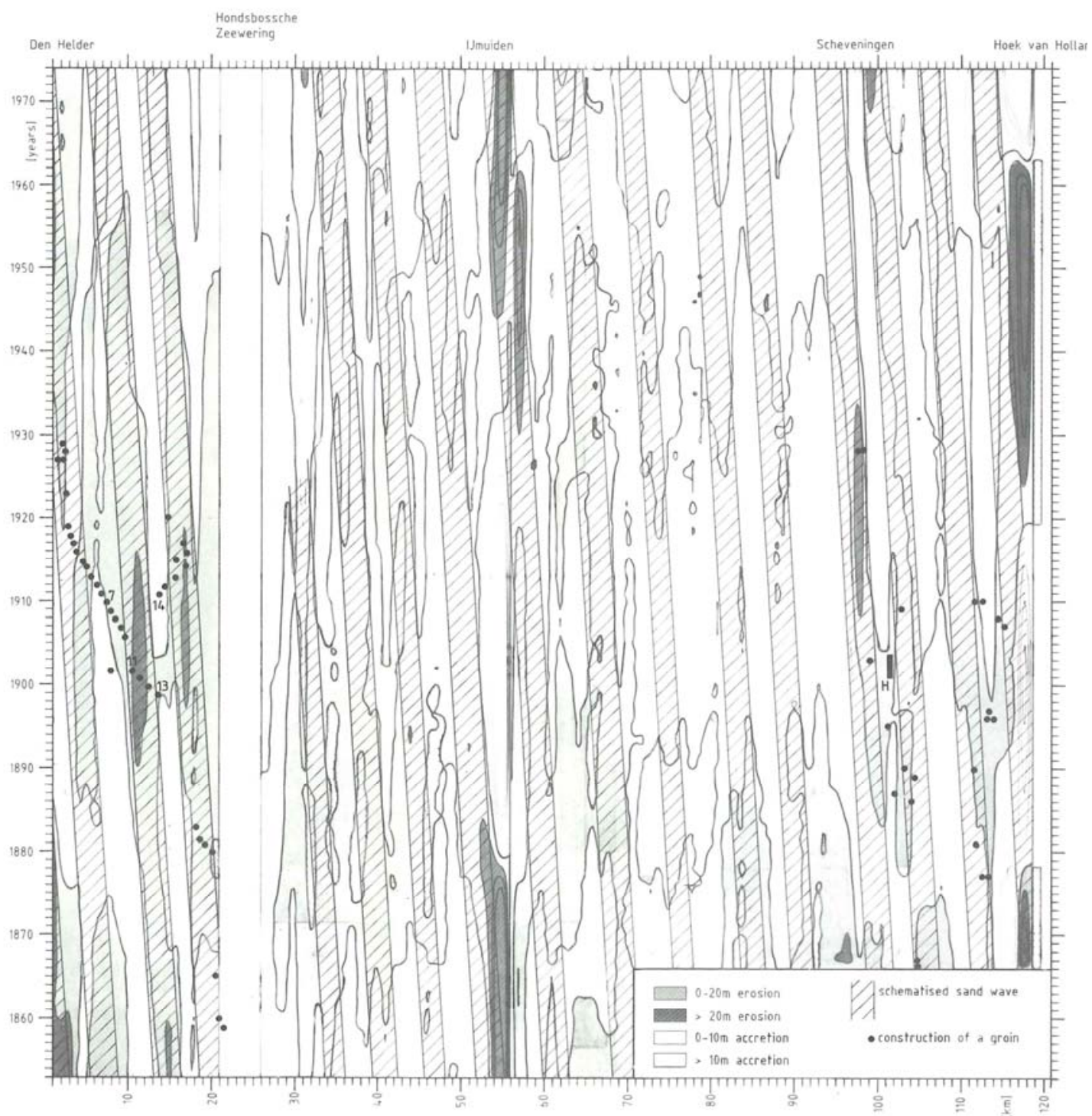

Figure 8: Isolines of coastal regression along the coast of Holland, corrected for changes in wind climate

\section{THE ORIGIN OF SAND WAVES}

In the preceding section, sand-wave kinematics have been described in detail. For operational coastal management this is quite satisfactory. A physical explanation, however, does not follow from the presented data. At the Wadden Isles in the north of The Netherlands, the presence of sand waves can be explained by sand banks moving from one island to another (in the direction of the longshore, surfinduced current, i.e. the bar-bypass system, see for example Bruun (1978), his p. 27). Along the coast of Walcheren there seems to be a correlation between the occurrence of sand waves and eroding and sedimentating zones in the outer delta. Along the coast of Holland there is no correlation with known physical phenomena. Some sand ridges have been observed (Wiersma and Van Alphen, 1988), but no correlation exists between the location of sand ridges and sand waves. Research on sand ridges along the coast of Holland has shown that sand ridges do not move, but sand waves do. Sand ridges occur between $\mathrm{km} 40$ and $\mathrm{km} \mathrm{90.} \mathrm{It} \mathrm{happens} \mathrm{that} \mathrm{this} \mathrm{section} \mathrm{of} \mathrm{the} \mathrm{coast} \mathrm{is} \mathrm{the} \mathrm{accreting} \mathrm{part} \mathrm{(north} \mathrm{of} \mathrm{km} 40$ and south of $\mathrm{km} 90$ there is a long-term linear coastal erosion) and also that in this section sand waves are less obvious.

\section{SAND WAVES ALONG OTHER STRETCHES OF THE DUTCH SHORELINE}

Besides coastal stretches discussed in this paper, sand waves can be observed also along other coastal sections in The Nether lands. The waves along the coast of Zeeuwsch-Vlaanderen, Goeree and Voorne are not yet studied, but based upon diagrams like Fig. 3a an estimate can be made of amplitude and celerity. Along the Wadden Isles sand waves are very clear, however an analysis amplitudes and 
celerities can be observed. Because of many disturbing effects in the extremely dynamic environment a clear analysis of the waves is more difficult. Based upon detailed and less detailed analysis of the Dutch shoreline, the summary of Table 1 can be made.

TABLE 1

Sand-wave characteristics along the Dutch coast

\begin{tabular}{|c|c|c|c|}
\hline Shoreline & $\begin{array}{c}\text { Amplitude } \\
(\mathrm{m})\end{array}$ & $\begin{array}{c}\text { Celerity } \\
(\mathrm{m} / \mathrm{yr})\end{array}$ & $\begin{array}{c}\text { Period } \\
(\mathrm{yr})\end{array}$ \\
\hline Schiermonnikoog & $50-850$ & $240-340$ & $50-100$ \\
Ameland & $25-2500$ & $310-450$ & $40-90$ \\
Terschelling & $15-1900$ & $240-400$ & $40-90$ \\
Vlieland & $25-600$ & $220-270$ & $60-80$ \\
Texel & $?$ & $?$ & $?$ \\
Coast of Holland & $40-\quad 60$ & 65 & $75-100$ \\
Voorne & $50-150$ & $130-160$ & $50-70$ \\
Goeree & $50-350$ & $220-300$ & 100 \\
Schouwen & $50-450$ & 90 & 4060 \\
Walcheren & $80-400$ & 45 & $120-150$ \\
Zeeuwsch-Vlaanderen & $20-200$ & 100 & 60 \\
\hline
\end{tabular}

\section{THE APPLICATION OF SAND-WAVE KINEMATICS}

At densely populated coasts, especially when they are eroding, it is necessary to know the evolution of the shoreline in the near future. In The Netherlands prediction of shoreline development is required mainly for two reasons. Dutch law requires a safety against inundation of 1 in 100,000. In some places a single dune row has to meet this requirement. Dune coasts which are not safe enough to withstand extreme storms have to be improved (see Van de Graaff, 1986).

Such an improvement is mostly done by placing more sand in the dune profile, either on the seaward or the landward side of the dune row. For economic reasons a prediction of the lifetime of these works has to be made. Especially works on the landward side (often causing demolition of houses) should have a lifetime of at least 20 years. In the past such works were often designed on the basis of linear coastal 'regression over the last 10- 15 years. This may cause incorrect decisions. In some places this leads to predictions which are up to $500 \mathrm{~m}$ wrong.

The second reason is the use of the coastal zone for other purposes than sea defense. In The Netherlands it is in principle not allowed to build houses, etc. on sea defense works, like dikes and dunes. Local authorities have to determine in their planning process which zone has to be reserved for sea defense. Generally a zone is reserved which might be necessary for sea defense in the next 50 years. In order to determine the width of this zone a prediction of the location of the shoreline in 50 years is requested, which is quite an impossible task for the coastal engineer. Accurate descriptions of sand waves may improve the quality of the predictions.

\section{GROINS}

In the northern part of Holland ( $\mathrm{km} 0-\mathrm{km}$ 21, between Den Helder and the sea dike of the Hondsbossche Zeewering) groins have been constructed in the beginning of this century. It is now possible to evaluate the effect of these groins on the long-term behaviour of the shoreline. Along this stretch, in 1898, a groin was constructed at $\mathrm{km} \mathrm{13.} \mathrm{This} \mathrm{groin} \mathrm{was} \mathrm{quite} \mathrm{successful.} \mathrm{In} 1907$ one could see a considerable improvement of the coast. Before the groin was built, the erosion was in the order of 1.3 $\mathrm{m} / \mathrm{yr}$. Between 1899 and 1907 there was an accretion of $70 \mathrm{~m}$, or nearly $9 \mathrm{~m} / \mathrm{yr}$. Based upon this success, in 1902 a groin was constructed at $\mathrm{km} \mathrm{11,} \mathrm{in} 1906$ at $\mathrm{km} 9$ and in 1910 at $\mathrm{km} 7$ and 14. Groin no. 11 was still successful, however, at groins no. 7 and 9 there was no improvement. Around 1915 a series of groins was constructed, and only the groin at $\mathrm{km} 14$ was successful.

Knowing the movement of the sand waves, the effect of the groins can be explained. In Fig. 8, dots indicate the construction of groins. Groins, constructed during, or just after the passage of the top of a sand wave are not successful. In Fig. 8 it can be seen that only groins no. 13, 11, and maybe 14 await an accretion period, and that especially groins no. 9 and 7 were constructed in a period in which erosion could be expected.

In the southern part of Holland (around km 100) groins have also been constructed. Here the same pattern can be observed. Groins were constructed during periods of erosion, after which accretion followed. However this accretion is not caused by the groin but by the movement of the sand wave. Even the construction of the harbour moles at Scheveningen (km 105.5, during 1901-1904, marked 
with an $\mathrm{H}$ in Fig. 8) does not have a major influence on adjacent coastal stretches, besides, as already indicated, before that the amplitude of the wave is increased after passing the breakwaters. The increase of amplitude may be caused by the fact that the definition of "shoreline" in Fig. 8 is the average of the HW and LW line. If the profile of the beach from dune foot to the end of the active zone is influenced by the harbour moles, the total amount of sand in the sand wave remains identical, only the wave becomes more apparent near the water line and less apparent at deeper water. From $\mathrm{km} 98.3$ up to 117 full profiles are available of every five year, starting in 1900. A more detailed analysis of those data may give an explanation of the increase of sand wave amplitude at the water line after passing a harbour mole.

It is also clear from Fig. 8 that groin construction did not influence the erosion and accretion pattern in the area. The sand waves apparent before 1900 have the same celerity, phase and amplitude as the wand waves in the period between 1920 and 1980. All changes observed in this stretch of shoreline can be related to physical phenomena, not related to the construction of the groins. From the above, one has to conclude that groin construction along the coast of Holland:

- did not change the linear long-term coastal erosion; and

- did not change the cyclic behaviour of the shoreline.

Consequently one has to conclude that the construction of groins on this coastal stretch did not have any effect at all.

\section{REFERENCES}

Allan, J.RL., 1980. Sand waves; A model of origin and internal structure. Sediment. Geol., 26: 281 328.

Bakker, W.T., 1968. A mathematical theory about sandwaves and its application on the Dutch Wadden Isle of Vlieland. Shore Beach, 36(2): 4- 14.

Bruun, P., 1954. Migrating sand waves or sand humps, with special reference to investigations carried out on the Danish North Sea Coast. In: Proc. 5th Int. Conf. Coastal Engineering, Grenoble, pp. 269- 295.

Bruun, P. and Manohar, M., 1963. Coastal protection for Florida. Florida Eng. Ind. Exp. Station, Gainesville, Fla. Bull. 113, 16 pp.

Bruun, P., 1978. Stability oflidal inlets. Elsevier, Amsterdam.

Lorin, J. and Migniot, C. 1984. Recul du trait de côte le long du littoral aquitain. XVIIIe journées de l'hydraulique, Marseille, Société hydrotechnique de France, pp. 11.6.1 -11.6.9.

Maranus, J.W. and Verhagen, H.J., 1987. Zandgolven en kustverdediging in Zeeland. Polytechnisch Tijdschrift/ Civiel, 42 (2): 34-38.

Ringma, S.H., 1950. Afneming Noorderstrand Walcheren nabij Oostkapelle. Rijkswaterstaat Vlissingen, Intern. Rep. 50-10.

Van de Graaff, ,J., 1986. Probabilistic design of dunes; an example from the Netherlands. Coastal Eng., 9(5): 479-500.

Van Straaten, L.M.J.U., 1961. Directional effects of winds, waves and currents along the Dutch North Sea coast. Geol. Mijnbouw, 40: 310-391.

Wiersma, J. and Van Alphen, J.S.J.L., 1987. The morphology of the Dutch Shoreface between Hook of Holland and Den Helder. In: P.L. de Boer (Editor), Tide-influenced sedimentary environment and facies. Reidel, Dordrecht, pp. $101-110$. 